\title{
A calcified sinutubular junction: the discovery of a supravalvular aortic stenosis in an elderly woman
}

\author{
L. Cozijnsen • M. Bakker-de Boo • J. J. Kardux • \\ B. J. Bouma \\ Published online: 3 May 2013 \\ (C) The Author(s) 2013. This article is published with open access at Springerlink.com
}

\begin{abstract}
We report a case of a 64 year old woman with a calcified ring at the level of the sinotubular junction. Echocardiography and Computed Tomography showed a supravalvular aortic stenosis, without known associated lesions, except for the existence of an aberrant right subclavian artery. These combination of abnormalities makes it an unique case. Differential diagnosis of sinutubular calcification is added. From the literature a short review of supravalvular aortic stenosis is presented with indications for surgical intervention. Lifelong and regular follow up is necessary.
\end{abstract}

\section{Introduction}

The best available evidence suggests that overall prevalence of congenital heart defect (CHD) in the adult population is about 3000 per million [1]. The population of adults with a congenital heart defect is increasing, due to improved survival after cardiac surgery [1, 2]. Supravalvular aortic stenosis (SVAS) is the least common form of left ventricular outflow tract (LVOT) obstruction. In Kitchiner's series the incidence of LVOT obstruction was $6.1 / 10,000$ live births. In his series of 313 patients with LVOT obstruction, SVAS

L. Cozijnsen $(\bowtie) \cdot$ M. Bakker-de Boo

Department of Cardiology, Gelre Hospital, Albert Schweitzerlaan

31, 7334 DZ Apeldoorn, the Netherlands

e-mail: 1.cozijnsen@gelre.nl

J. J. Kardux

Department of Radiology, Gelre Hospital, Apeldoorn, the

Netherlands

B. J. Bouma

Department of Cardiology, Academic Medical Centre,

Amsterdam, the Netherlands occurred in $7.7 \%$ of the cases [3]. In 51 children, catheterised for congenital aortic stenosis, Liu detected 7 cases $(13.7 \%)$ of SVAS [4]. SVAS involves a focal or diffuse narrowing of the ascending aorta, starting at the sinotubular (ST) junction. It can be a feature of the Williams-Beuren syndrome (WBS) [5], an autosomal dominant multisystem disorder involving besides cardiovascular abnormalities, also mental retardation, characteristic facial appearance ('elfin face') and occasional idiopathic hypercalcaemia. SVAS can also occur in an autosomal inherited form without the features of the WBS or in a rare sporadic form [6]. In all three types, there is a mutation of the elastin gene on chromosome $7 \mathrm{q} 11.23[5,6]$. SVAS is also reported to occur in association with homozygous (44\%) [7-9] or heterozygous (4\%) familial hypercholesterolaemia (FH) [9].

\section{Case}

A woman, 64 years of age, was sent to our outpatient clinic for evaluation of a cardiac murmur. She had no cardiac complaints and no family history of cardiac abnormalities. The medical history revealed only hypercholesterolaemia and hypertension. For the latter she was on perindopril $4 \mathrm{mg}$ daily. She had a normal facial appearance and normal intellect. Her blood pressure, measured at the right and left arm, was $180 / 90$ and $160 / 90 \mathrm{mmHg}$ respectively. Her weight was $78 \mathrm{~kg}$. A grade $2 / 6$ early- and mid-systolic murmur was heard at the 2nd intercostal space on the right side and at the 4 th intercostal space on the left side of the chest. No other abnormalities were found on physical examination. The laboratory investigation showed an elevated total cholesterol and low-density lipoprotein cholesterol level in the plasma of 7.0 and 

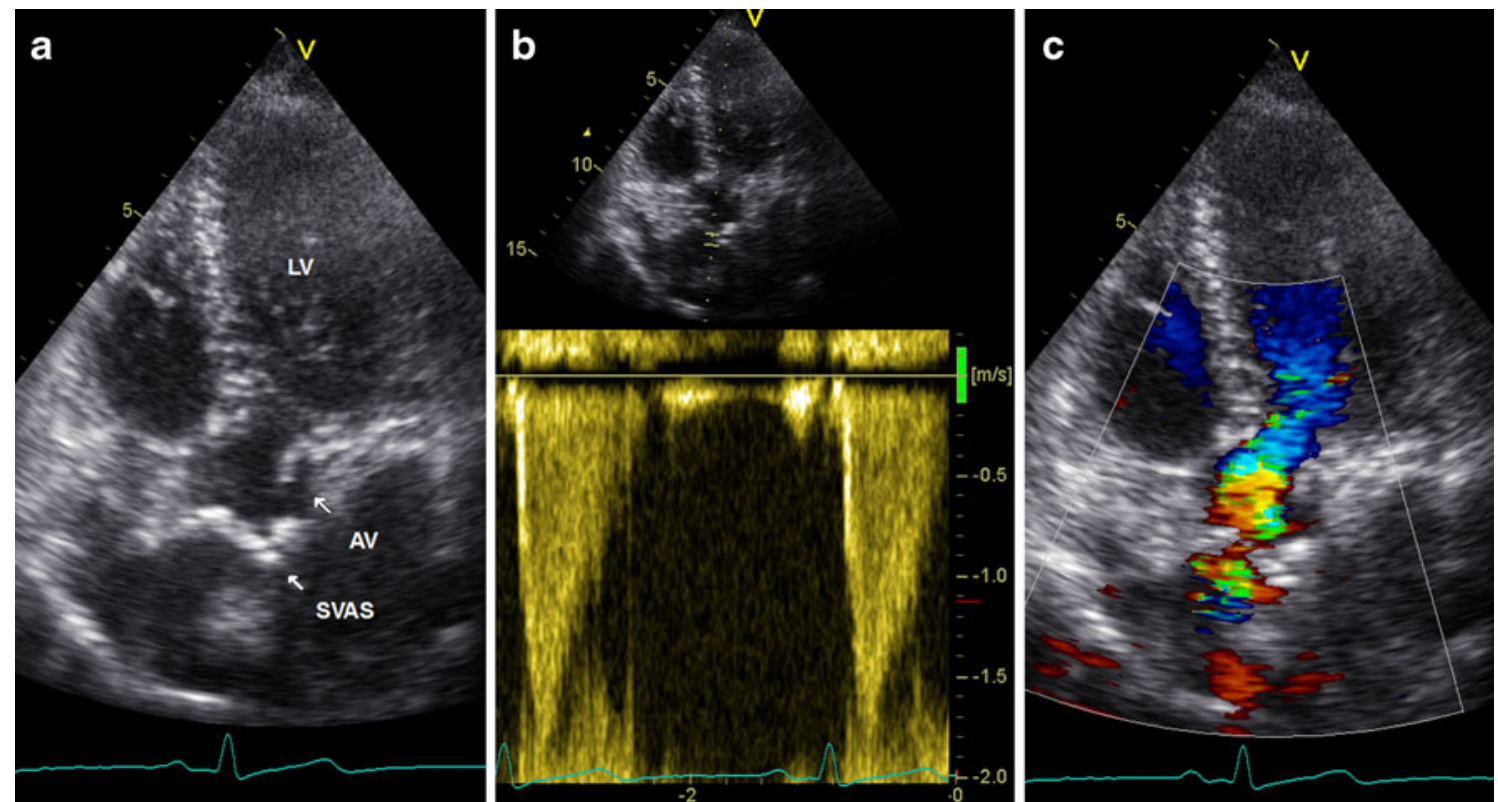

Fig. 1 Cardiac echocardiography with apical views demonstrating the SVAS (a, left, arrow). Pulsed-wave Doppler measurement shows a maximal velocity of $1.8 \mathrm{~m} / \mathrm{s}$ across the stenosis (b, middle). Colour Doppler visualises the turbulence at the level of the ST junction (c, right)

$4.4 \mathrm{mmol} / 1$, respectively. High-density lipoprotein cholesterol and triglycerides levels were normal. The electrocardiogram was completely normal, without signs of left ventricular (LV) hypertrophy. Echocardiography showed a short circular stenosis at the level of the ST junction, with a small pressure gradient. The maximal flow velocity (V-max) at the level of the SVAS was $1.8 \mathrm{~m} / \mathrm{s}$ (Fig. 1). Besides some mild mitral and tricuspid incompetence, no intracardiac abnormalities were seen. The aortic valve (AV), although not optimally visualised on echocardiography, was proven tricuspid and normal at computed tomography $(\mathrm{CT})$. Also a calcified ring could be imaged at the level of the ST junction with a minimum diameter of $1.7 \mathrm{~cm}$, followed by a mild poststenotic dilatation of the tubular ascending aorta of $3.9 \mathrm{~cm}$. There were no calcifications elsewhere in the thoracic aorta (Figs. 2 and 3a). Associated lesions as accompanying supravalvular stenosis of the pulmonary
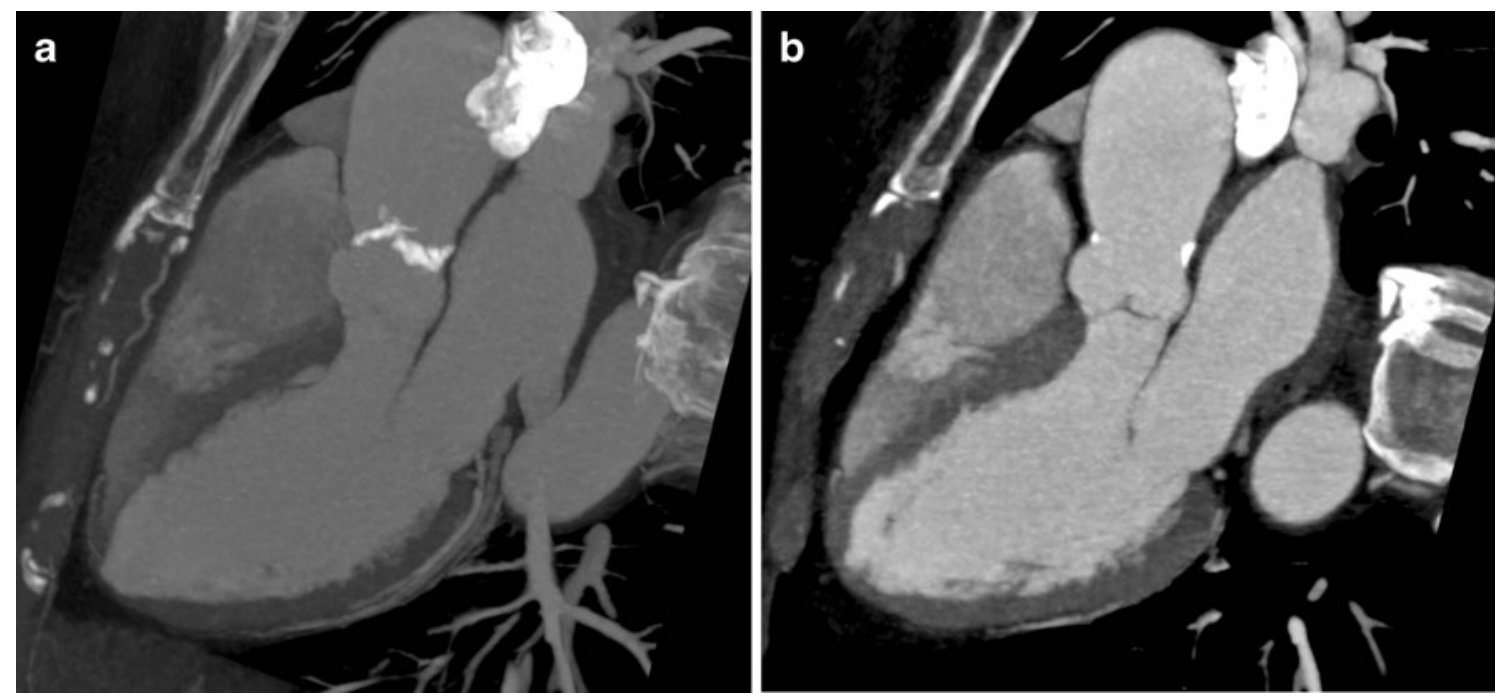

Fig. 2 CT images in a three-chamber plane. Thick $(\mathbf{a}, l e f t)$ and thin $(\mathbf{b}$, right $)$ slice maximum intensity projection (MIP) reconstructions, visualising the calcified ST ridge 

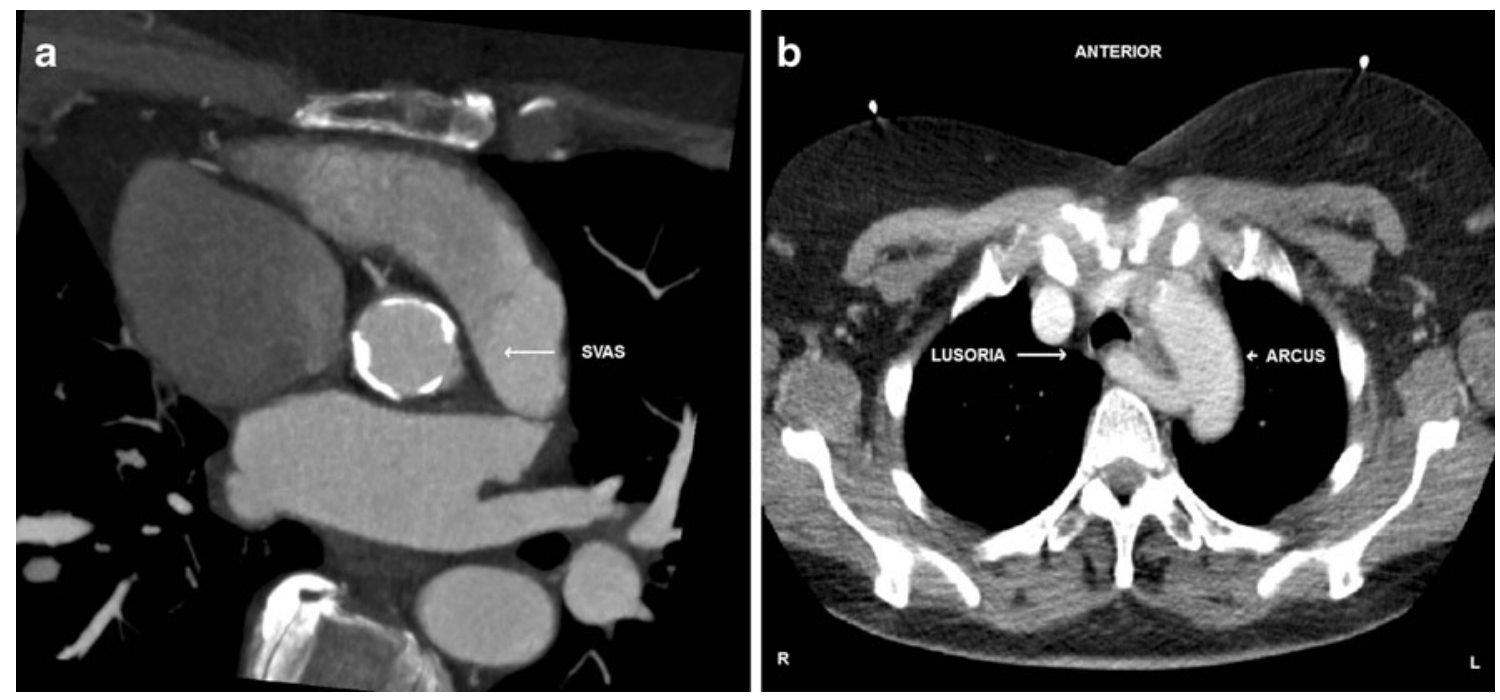

Fig. 3 CT MIP reconstructions. Axial-oblique plane (a, left) showing the calcified ring (arrow, SVAS) and axial plane (b, right) showing the aberrant right subclavian artery (arrow, LUSORIA) originating from the distal arcus aortae (arrow, ARCUS)

trunk, aortic coarctation, persisting ductus arteriosus, and pulmonary stenosis were excluded by contrast-enhanced CT. However, the patient did have an aberrant origin of the right subclavian artery (arteria lusoria) (Fig. 3b).

\section{Discussion}

SVAS can occur as a localised fibrous diaphragm just distal to the coronary ostia, as an external hourglass deformity with a corresponding luminal narrowing of the aorta, or as a diffuse narrowing of the ascending aorta. In this specific case of SVAS the form of the calcified ring cannot to be classified in one of the three aforementioned categories. Such a case has never been published before. The family history revealed no cardiac disorders and no familial hypercholesterolaemia (FH). So in our patient there is a sporadic form of SVAS.

A PubMed search found no earlier publications of a 'supravalvular' or 'supravalvar' aortic stenosis in the form of a 'calcified/calcific ring', nor an association with an aberrant right subclavian (artery) or a lusoria (artery) [10]. A case report was recently published of a 6-year-old girl with familial SVAS and a total occlusion of the brachiocephalic trunk [11]. Calcification of the ascending aorta has been reported in combination with a diffuse type SVAS and in patients with homozygous FH. Calcification limited to portions of the ST ridge has been reported with preference for the right sinus of Valsalva [12]. These lesions has been described as a marker of severe aortic plaque formation
[13]. Other investigators demonstrated that these lesions were distinct from aortic atheromatous disease and were histologically similar to AV calcifications [14]. Because of the demonstrated mild stenosis with turbulence, our patient must be diagnosed as SVAS. We hypothesise that our patient originally had a discrete fibrous stenosis. Mechanical stress has successively led to inflammation, interstitial cell activation, osteogenic differentiation and ultimately calcification [15].

Surgery for SVAS is indicated in patients with symptoms and mean Doppler gradient $\geq 50 \mathrm{mmHg}$ [16]. Or $<50 \mathrm{mmHg}$ with symptoms and/or LV systolic dysfunction and/or LV hypertrophy or when coronary bypass operation is indicated [16]. The optimal surgical procedure for repair is still under debate [6]. In a retrospective study in 75 patients with discrete stenosis, multisinus aortoplasty resulted in better haemodynamics and in reductions in both the need for reoperation and the mortality rate when compared with patch enlargement of the noncoronary sinus only [17]. However, these results did not reach statistical difference [6]. In other studies, the sample size was even smaller, related to the rarity of the lesion which makes statistical analysis and generalisation of the findings a challenge. Hence the ESC Guidelines do not favour a specific surgical technique [16].

Because there is no significant pressure gradient over the SVAS in our patient, the treatment could be conservative. In a recent publication, Greutmann et al. showed that progression of SVAS in adulthood is rare. Adverse events are associated with valve disease, particularly the mitral valve 
[18]. The mechanism of the dilatation of the tubular ascending aorta can be a jet lesion. Also elastin aortopathy is a possibility. Follow-up remains necessary with specific attention for progression of the obstruction (rare), development of aneurysm [19] and coronary artery disease (elevated prestenotic pressure) [16].

\section{Conclusion}

Improvement of contemporary imaging modalities (echocardiography, CT and also magnetic resonance imaging) will increase the discoveries of unknown congenital cardiovascular abnormalities, also later in life. For SVAS, lifelong and regular follow-up is necessary for the development of poststenotic dilatation and coronary artery disease.

Funding None.

Conflict of interests None declared.

\section{Disclosures None}

Open Access This article is distributed under the terms of the Creative Commons Attribution License which permits any use, distribution, and reproduction in any medium, provided the original author(s) and the source are credited.

\section{References}

1. Mulder BJ. Epidemiology of adult congenital heart disease: demographic variations worldwide. Neth Heart J. 2012;20:505-8.

2. Freling HG, van Slooten YJ, van Melle JP, et al. Prosthetic valves in adult patients with congenital heart disease: rationale and design of the Dutch PROSTAVA study. Neth Heart J. 2012;20:419-24.

3. Kitchiner D, Jackson M, Malaiya N, et al. Incidence and prognosis of obstruction of the left ventricular outflow tract in Liverpool (1960-91): a study of 313 patients. Br Heart J. 1994;71:588-95.
4. Liu CW, Hwang B, Lee BC, et al. Aortic stenosis in children: 19year experience. Zhonghua Yi Xue Za Zhi. 1997;59:107-13.

5. Pober BR. Williams-Beuren syndrome. N Engl J Med. 2010;362:239-52.

6. Stamm C, Friehs I, Ho SY, et al. Congenital supravalvar aortic stenosis: a simple lesion? Eur J Cardiothorac Surg. 2001;19:195-202.

7. Brook GJ, Keidar S, Boulos M, et al. Familial homozygous hypercholesterolemia: clinical and cardiovascular features in 18 patients. Clin Cardiol. 1989;12:333-8.

8. Summers RM, Andrasko-Bourgeois J, Feuerstein IM, et al. Evaluation of the aortic root by MRI: insights from patients with homozygous familial hypercholesterolemia. Circulation. 1998;98:509-18.

9. Rallidis L, Naoumova RP, Thompson GR, et al. Extent and severity of atherosclerotic involvement of the aortic valve and root in familial hypercholesterolaemia. Heart. 1998;80:583-90.

10. Myers PO, Fasel JH, Kalangos A, et al. Arteria lusoria: developmental anatomy, clinical, radiological and surgical aspects. Ann Cardiol Angeiol. 2010;59:147-54.

11. van Oort AM, Willemsen M. Supravalvular aortic stenosis and total occlusion of the brachiocephalic trunk. Neth Heart J. 2010;18:327-8.

12. D'Cruz IA, Calderon E, Clark R. Transthoracic echocardiographic visualization of calcification of the sinotubular ridge of the ascending aorta. Echocardiography. 1998;15:425-8.

13. Finkelhor RS, Youssefi ME, Mohan SK, et al. Aortic sinotubular junction calcium as a marker of severe aortic atherosclerosis. Am J Cardiol. 1998;82:1549-52.

14. Tveter KJ, Edwards JE. Calcified aortic sinotubular ridge: a source of coronary ostial stenosis or embolism. J Am Coll Cardiol. $1988 ; 12: 1510-4$

15. Riem Vis PW, van Rijswijk JW, Chamuleau SA, et al. The pathophysiological basis of pharmacological interventions in CAVD. Neth Heart J. 2012;20:270-8.

16. Baumgartner H, Bonhoeffer P, De Groot NM, et al. ESC Guidelines for the management of grown-up congenital heart disease (new version 2010). Eur Heart J. 2010;31:2915-57.

17. Stamm C, Kreutzer C, Zurakowski D, et al. Forty-one years of surgical experience with congenital supravalvular aortic stenosis. J Thorac Cardiovasc Surg. 1999;118:874-85.

18. Greutmann M, Tobler D, Sharma NC, et al. Cardiac outcomes in adults with supravalvar aortic stenosis. Eur Heart J. 2012;33:2442-50.

19. Cozijnsen L, Braam RL, Waalewijn RA, et al. What is new in dilatation of the ascending aorta? Review of current literature and practical advice for the cardiologist. Circulation. 2011;123:924-8. 